\title{
Ideología y discurso lingüístico: la Etnortografía como subdisciplina de la glotopolítica
}

\author{
María Luisa Calero Vaquera* \\ Universidad de Córdoba, España
}

\begin{abstract}
Resumen
Se han dedicado ya numerosos estudios a la (¿inevitable?) presencia de carga ideológica en obras lexicográficas (de lo que se ocupa la Etnolexicografía) y, en menor medida, en tratados gramaticales (lo que hemos denominado Etnogramática). En este trabajo pretendemos completar esta mirada etnolingüística revisando un manual ortográfico de la segunda mitad del siglo XX (el Plan concéntrico de ortografía del inspector de enseñanza primaria Nicasio H. García) publicado en Montevideo en 1947 ( $2^{\mathrm{a}}$ edición), donde es posible identificar ciertas marcas textuales que plasman un determinado contexto político y sociocultural. Se propone aquí, en consecuencia, la creación de una nueva subdisciplina, hermana de las anteriores, que podemos llamar Etnortografía, todas ellas formando parte de la Glotopolítica, como ciencia que estudia las diversas maneras en que la sociedad actúa sobre las lenguas.
\end{abstract}

Palabras clave: etnolingüística, glotopolítica, ortografía, didáctica del español.

* Para correspondencia, dirigirse a: María Luisa Calero Vaquera (mlcalero@uco.es), Departamento de Ciencias del Lenguaje, Facultad de Filosofía y Letras, Universidad de Córdoba, Plaza del Cardenal Salazar, s/n, 14071 Córdoba, España. 


\title{
IDEOLOGY AND LINGUISTICS DISCOURSE: THE ETHNORTHOGRAPHY AS A SUBDISCIPLINE OF GLOTOPOLITICS
}

\begin{abstract}
Numerous studies have focused on the (inevitable?) ideological bias present in lexicographic works - as approached by Ethnolexicographyand, to a lesser extent, in grammatical treatises -what is now called Ethnogrammar. Our aim in this paper is to contribute a review of an orthographic handbook to that ethnographic area, entitled Plan concéntrico de ortografia -written in the second half of the 20th c. by Nicasio H. García, an inspector of Primary Education, and published in Montevideo in 1947 ( $2^{\text {nd }}$ edition). A number of textual features in this book reflect the specific political and socio-cultural context. In the present study, therefore, we put forward the creation of a new sub-discipline, akin to those already mentioned, which can be named Ethnorthography, also included in the super-ordinate Glotopolitics, the science that addresses the various ways in which society acts upon languages.
\end{abstract}

Key words: ethnolinguistics, glotopolitics, orthography, didactics of Spanish.

Recibido: 28/06/10. Aceptado: 30/09/10.

\section{IDEOLOGÍA Y DICCIONARIO}

No es novedad el estudio de las marcas ideológicas ${ }^{1}$ en obras de carácter lingüístico, como pueden ser los diccionarios, las gramáticas y, en menor medida, las publicaciones de tema ortográfico. En cuanto a los primeros, mucha tinta se ha vertido en la bibliografía especializada española (Ahumada

1 Valga como definición de ideología la propuesta por Teun A. van Dijk (1998: 21): “[...] las ideologías se pueden definir sucintamente como la base de las representaciones sociales compartidas por los miembros de un grupo. Esto significa que las ideologías les permiten a las personas, como miembros de un grupo, organizar la multitud de creencias sociales acerca de lo que sucede, bueno o malo, correcto o incorrecto, según ellos, y actuar en consecuencia" [cursiva del autor]. 
Lara 2006: 41-42) intentando dilucidar si es conveniente o reprobable (y, en ese caso, si es evitable) la aparición de huellas ideológicas en las obras lexicográficas: desde aquellos especialistas que han abogado por una neutralidad impoluta del redactor del diccionario (Seco 1987 o Casares 1992) hasta quienes justifican y se muestran más flexibles con la aparición de improntas ideológicas en este tipo de obras (Blecua Perdices 1990, Forgas Berdet 1996 y 2001, o Pascual y Olaguíbel 1992), sus diferentes opiniones han dado lugar a un debate metalexicográfico de primer orden. Compárense dos muestras de sendas tendencias:

Si a las palabras [en el discurso] les está permitido ser cariñosas, encomiásticas, despectivas o irónicas, al lexicógrafo no le es lícito imitarlas. En su vida privada, en sus ratos de ocio, el redactor de un diccionario puede escribir páginas coloristas, inventar arriesgadas metáforas, componer versos gongorinos o sentar plaza de humorista; puede, en suma, dar curso libre y expresión cumplida a su particular idiosincrasia y crearse un estilo que lleve el sello inconfundible de la personalidad de su autor; pero todo esto deberá dejarlo en el guardarropa antes de entrar en la oficina lexicográfica (Casares 1992: 142).

El perfil ideológico del autor o autores (de un diccionario) y el del grupo social al que pertenecen influye en la tarea lexicográfica desde el momento mismo de la concepción de la obra, puesto que cada una de las decisiones que conlleva su factura es una decisión marcada ideológicamente (Forgas 2001: s.p.).

Es cierto que ha habido otros momentos de la historia de la lexicografía (sobre todo en las etapas iniciales, y no solo de la lexicografía española) en los que era aún más evidente que en la actualidad la intromisión de una determinada ideología en los textos. Así, contamos con estudios bien documentados y demostrativos de que la expresión de credos políticos, orientaciones filosóficas o dogmas religiosos se inmiscuyó descaradamente tanto en la macroestructura (presentación, prólogo, observaciones preliminares, etc.) como en la microestructura (cuerpo de la definición, textualizaciones y ejemplos) de esos primeros testimonios lexicográficos. Rodríguez Barcia (2008), por ejemplo, ha analizado el caso de las sucesivas ediciones del diccionario de la Real Academia Española, que con razón considera

[...] especialmente interesante, pues desde siempre su trabajo estuvo vinculado a los grupos que ostentaban el poder político, religioso y social, con lo que la cosmovisión de los redactores coincidía en parte con la ideología de la que participa la 'elite', por lo que el estudio de la 
producción lexicográfica de esta institución puede revelar aspectos de gran interés para el dibujo de la sociedad española (Rodríguez Barcia 2008: 13).

Es innegable que la producción lexicográfica actual ha conseguido atemperar (que no eliminar) las marcas ideológicas presentes en toda producción humana; pero, como explica Medina Guerra (2003), tanto los criterios editoriales como las personas que redactan el diccionario, así como el público al que éste va dirigido siguen siendo en la actualidad factores determinantes de la ideología que subyace en las páginas de cualquier diccionario. Recuérdense, si no, las polémicas que hoy día suscita el sesgo ideológico de la Academia en su tratamiento y representación de las mujeres en el texto lexicográfico (Lledó 2004). Como cualquier producto cultural, el diccionario nace per se con una marca ideológica, sutil a veces, pero siempre ineluctable. Es lo que ha llevado a algunos especialistas (sobre todo de Hispanoamérica, por ejemplo, Pérez Hernández 1997) a utilizar, para designar este tipo de estudios, el término de Etnolexicografía ${ }^{2}$ o Socioetnolexicografia,

[...] acercamiento que pretende respaldar la idea de que los diccionarios, más que puros instrumentos de descripción aséptica y objetiva de las lenguas, son textos que ofrecen una particular e ideológica visión del mundo y de la historia, cultura y sociedad de los hombres (Pérez Hernández 2000: 59).

\section{IDEOLOGÍA Y GRAMÁTICA}

Como producto cultural que son, también los libros de gramática son igualmente susceptibles de presentar en sus páginas marcas ideológicas, orientaciones de pautas de conducta, indicaciones morales, etc. Ya en 1984, M. Martinell advertía sobre la intención didáctico-moralizadora que albergaban muchos de los ejemplos contenidos en la Gramática académica de 1796:

2 Término que también utilizábamos en Calero Vaquera (2004: 324). 
La virtud, la justicia, el estudio y la milicia son en este caso temas privilegiados, sin que falten las alusiones o la presencia de otros temas como la familia, las riquezas o la vida humana [...]. Juicios de valor, generalizaciones, sentencias, presentación de hechos concretos, así como recursos retóricos, todo vale para transmitir unos valores, una tradición, y para inculcar unas actitudes (Martinell 1984: 168-169).

Proceder que, desde luego, no era exclusivo de la Real Academia sino más bien una práctica generalizada entre los autores de la tradición hispánica, como demuestra la siguiente cita (una de las muchas posibles) de un gramático español del siglo XIX:

Se han escogido cuidadosamente ejemplos de buen gusto, [...] para comprobar las observaciones del texto, teniendo además la ventaja de envolver los más de ellos un pensamiento o máxima moral, que al propio tiempo que sirve para ilustrar la razón de los niños, pueda insensiblemente ir formando también su corazón (de Miguel 1882: xi).

La misma costumbre es apreciable en las gramáticas editadas en Hispanoamérica, hecho que se condice con la magnitud e intensidad de los acontecimientos sociopolíticos que tuvieron lugar en esa región, especialmente a lo largo del siglo XIX. Así lo demuestra Narvaja de Arnoux (2008: 285), quien recientemente ha dedicado unas páginas a "indagar las características y función de los ejemplos en el modelo de gramática escolar [en el Chile de 1842 a 1862] destinado a la consolidación del Estado nacional y a la ampliación del sistema educativo". Para ello se centra en el análisis específico de los manuales de gramática que Andrés Bello publicó con vistas a la enseñanza escolar ${ }^{3}$ chilena, donde los textos que le sirven de ejemplos se nos muestran notablemente "sacralizados" ("por penetración del discurso religioso", Narvaja de Arnoux 2008: 290), marcados por las recomendaciones y advertencias morales ("los ejemplos no solo deben ilustrar los principios gramaticales sino también deben indicar las conductas esperadas", ibíd.) y, cómo no, repletos de consignas de amor a la propia patria chilena, recién independizada ("[la escuela] ha sido el 'santuario' del patriotismo", ibíd.). Bello, entre otros representantes del movimiento ilustrado en tierras de

Los titulados Gramática Castellana para el uso de las escuelas (1851) y Compendio de Gramática Castellana escrito para el uso de las escuelas primarias (1861). También Bello, al parecer, estuvo trabajando en sus años finales de vida en un nuevo texto de gramática escolar, Gramática Castellana, pero éste "permaneció inédito hasta 1937, año en el cual es publicado por Miguel Luis Amunátegui Reyes" (Narvaja de Arnoux 2008: 283). 
Hispanoamérica, se propuso, a la vez que difundir el conocimiento entre el mayor número posible de sectores sociales, la tarea de "disciplinar sujetos y prácticas" (Narvaja de Arnoux 2008: 308). De modo que algunas de las funciones en esa disciplina y "sujetamiento" de los individuos, propias de las "instituciones que tienen el monopolio del discurso moral" (i.e., la Iglesia y la familia), terminarán siendo "asumidas por el aparato escolar" (Narvaja de Arnoux 2008: 287). Las conclusiones del trabajo de Elvira Narvaja, aunque, como se ha dicho, centrado en las gramáticas escolares de Bello, permiten ser extrapoladas a otros muchos casos de autores de gramáticas didácticas:

El autor de la gramática escolar produce, a partir de su propia competencia discursiva, el enunciado ejemplificador pero al hacerlo tiene en cuenta [...] no solo la posibilidad de que este ilustre adecuadamente la regla gramatical sino también de que sea ejemplar en el campo social. Este imperativo se manifiesta en la abundancia de ejemplos que constituyen reglas y modelos de conducta moral, cívica o religiosa. En estos casos el gramático recurre a máximas, sentencias, aforismos, refranes, enunciados patrióticos estereotipados, que en su conjunto conforman un entramado cuyo recorte, textura y condensación en torno a ciertos ejes temáticos remiten a la ideología de una clase en un momento histórico (Narvaja de Arnoux 2008: 296).

Un caso especial de plasmación ideológica en tratados gramaticales suscitó nuestro interés hace unos años (Calero Vaquera 2004), en gran parte debido al procedimiento "simbólico" que utilizaba el autor, Cosme Pérez Cuadrado, en su manual titulado Curso superior de Gramática española simbólica e intuitiva (1946). Ahí se establecía, con fines declaradamente pedagógicos, una ingeniosa correspondencia (metafórica) entre las funciones que desempeñan las diferentes partes de la oración y las que, en el ámbito social, ejercen los diversos miembros de una familia, traduciendo así fenómenos abstractos en experiencias concretas, por lo que éstas tienen de más fácil asimilación por parte de los estudiantes ${ }^{4}$ : de tal manera que el sustantivo, "que es independiente en la oración [...] lo es en la misma forma que el cabeza de familia de que nadie depende" (Pérez Cuadrado 1946: 22); el adjetivo, "que no va solo, sino calificando o determinando al substantivo, lo hace en la misma forma que la esposa que no debe ir sola, sino unida a su esposo (el sustantivo)" (ibíd.) y así sucesivamente con el resto de las

\footnotetext{
4 Puede verse una técnica simbólica y "alegorizante" similar en el libro de la gramaticografía occitana medieval titulado Leys d'Amors, cuyo texto ha sido estudiado por Swiggers y Lioce (2003).
} 
partes oracionales. Este recurso didáctico, por el que se establecen correlatos entre el plano lingüístico y el plano sociocultural, permite rastrear datos y elementos del ámbito cultural, ideológico, etc. de una época determinada en obras gramaticales de la tradición. Y todo ello porque

Creemos que, al igual que sucede con el lexicógrafo, el autor de un tratado gramatical es hijo de su tiempo, de su cultura y de su sociedad y se encuentra, por tanto, sometido a unos modelos y estereotipos socioculturales que en ocasiones (de forma consciente o inconsciente) emergen y quedan plasmados en su producción científica. Los datos de índole cultural que a veces, en mayor o menor grado, se deslizan en los libros de gramática nos parecen valiosos en la medida en que pueden ir aportando una información extralingüística (no pocas veces "involuntaria") que permite ubicar en unas coordenadas espaciales y temporales a la obra en cuestión, y todo ello de forma paralela y complementaria a la información "voluntariamente" suministrada a través de los contenidos puramente gramaticales (Calero Vaquera 2004: 323-324).

Al tenor de estas reflexiones, reivindicábamos un nuevo espacio disciplinar que comprendería el estudio de cómo las costumbres, el saber, las experiencias, los comportamientos, la ideología, etc. de una determinada sociedad se plasman en las correspondientes obras gramaticales. Para esa nueva disciplina proponíamos de modo provisional el término Etnogramática ${ }^{5}$ (o Socio-etnogramática), la que se trataría de una disciplina de carácter metalingüístico, ya que, al igual que la Etnolexicografía, se ocuparía del discurso lingüístico como producto de una reflexión sobre la lengua.

\section{IDEOLOGÍA Y ORTOGRAFÍA}

También los manuales de ortografía, al igual que los diccionarios, las gramáticas y otros textos usados en las escuelas (por ejemplo, los libros para la enseñanza de la lectura, vid. Mirta et al. 2000), pueden informarnos acerca de la concepción del mundo, ideales, aspiraciones, etc. que los educadores de épocas pasadas transmitían a los jóvenes estudiantes para

5 Entendido el elemento compositivo gramática en su acepción de "libro donde se analizan los elementos de una lengua y sus combinaciones". 
que los interiorizaran y los mantuvieran vigentes a lo largo de su vida. Analizamos aquí un manual ortográfico de la lengua española que puede ser buena muestra de lo que se acaba de señalar: el titulado Plan concéntrico de ortografía. Curso elemental, publicado en Montevideo en 1947 ( $2^{\mathrm{a}}$ ed.). Del autor, Nicasio H. García, sabemos que fue profesor de Metodología en los Institutos Normales y que llegó a ocupar el cargo de Presidente del Consejo de Enseñanza Primaria de su país ${ }^{6}$. De la obra, que se inscribe en el denominado "sistema" o "plan concéntrico" educativo que comenzó a aplicarse en algunos países del Cono Sur americano (como Chile o Uruguay) en los años ochenta del siglo XIX, inspirado en los sistemas formativos que por entonces tenían vigencia en Alemania, Francia e Inglaterra. Este nuevo plan pedagógico, que vino a sustituir a la caduca enseñanza de materias aisladas e independientes unas de otras por la instrucción simultánea en varias secciones, pretendía conseguir que

todos los ramos de enseñanza, siguiendo direcciones paralelas desde el $1^{\mathrm{o}}$ hasta el último año de Humanidades, vayan ensanchando paulatinamente su esfera, y habiliten de este modo al alumno para que, después de haber empezado conociendo sólo las verdades elementales de la ciencia, abrace al terminar el curso la verdad completa en todas sus manifestaciones (Celis p. 6).

En concreto, el plan dividía los estudios de humanidades en dos ciclos de tres años cada uno, siguiendo en el primero el método deductivo (donde prevalece el acopio de hechos) y en el segundo el método inductivo (con exposición de los principios).

Conviene hacer aquí una breve referencia de tipo contextual: esta obra de 1947 ( $2^{\mathrm{a}}$ ed.) se inscribe en la estela dejada por el plan de reforma de la enseñanza primaria conocido como "Reforma Valeriana" (1876-1879). Incluso en la consideración de cualquier texto escolar publicado en Uruguay en tiempos cercanos, como es el caso, parece ineludible una mención, por mínima que sea, al que se considera - pese a su corta vida-el gran reformador de la escuela pública en ese país, José Pedro Varela (1845-1879). Ello, porque el mito del Uruguay democrático y culto de gran parte del siglo XX fue en gran medida un producto de aquella reforma educativa del XIX, que transformó profundamente no solo el sistema de enseñanza de la época

6 Cuando publica la 2 a edición (1947) de este manual ortográfico era "Inspector Regional de Enseñanza Primaria y ex Profesor de Metodología en los Institutos Normales”, según consta en la portada. 
sino el conjunto de las estructuras socioculturales, económicas y políticas del país entero. En efecto, aquel joven sociólogo y periodista, José Pedro Varela, desde su cargo político como Director de Instrucción Pública, fue el más directo responsable de la promulgación del Decreto Ley de Educación Común (1877), que abrió la senda para hacer realidad los ideales formativos de la Sociedad de Amigos de la Educación Popular, asociación que él mismo había fundado en 1868 junto a otros compatriotas suyos, y que abogaba por una educación universal (ya no en manos de unos pocos privilegiados) como base de la democracia y como la gran igualadora de las diferencias sociales. En efecto, mediante el citado decreto ley conseguiría implantar en el país una educación gratuita, obligatoria y laica ${ }^{7}$ para todos los sectores de la sociedad. Y, lo que no fue menos importante, gracias a esta normativa se lograba concentrar en manos del Estado el monopolio (esto es, el control) de la formación intelectual de los uruguayos. La enseñanza se convertía, así, en un deber más del Estado, cuyos responsables pronto vislumbraron una inmejorable ocasión para inculcar a la ciudadanía un creciente espíritu nacionalista, en un momento histórico de "transición entre el viejo país criollo y el nuevo Uruguay" (cit. por Fernández et al. 2000: 3). Por otra parte, aunque en estrecha relación con lo anterior, los gobernantes de la época siempre fueron conscientes de que tenían en sus manos la mejor herramienta para homogeneizar la diversa realidad social, étnica y cultural que en aquel momento histórico conformaba el país llamado Estado Oriental del Uruguay (piénsese que en 1884 el 44\% de los habitantes de la capital del Estado, Montevideo, era de procedencia extranjera). Con la consecución de ambos objetivos (es decir, la construcción de una identidad nacional y la homogeneización de una población tan variada) se pretendía "salvar nuestra idiosincrasia, defenderla de los terribles peligros a que está expuesta, provocar admiración por ella" (Zarrilli y Abadíe Soriano 1943: 10).

Volviendo a la obra que nos ocupa, el Plan concéntrico de ortografía. Curso elemental (Montevideo, 1947) de Nicasio H. García, nos interesa aquí por constituir un nuevo ejemplo de manual escolar donde ha quedado impresa una determinada huella ideológica, en la línea de lo visto en los párrafos precedentes. Si más arriba mostrábamos que esas huellas abundan en las obras de carácter lexicográfico o gramatical, ahora tendremos ocasión de comprobar que en los textos de tema ortográfico también sus autores se pueden ver tentados a introducir información cargada de ideología con la

\footnotetext{
7 Aunque, de hecho, la laicidad tardara en implantarse debido a la resistencia de la Iglesia católica, sí consiguió desterrar el predominio de la educación privada católica.
} 
finalidad de dirigir interesadamente el pensamiento y la conducta de sus pequeños lectores. Pero, ¿de qué manera y con qué instrumentos discursivos? Veámoslo.

No se trata aquí, en este manual uruguayo, de proponer una reforma ortográfica más, con la idea de simplificar la ortografía del español (una ortografía considerada por no pocos educadores irracional y caprichosa, que incluso puede derivar en discriminaciones de índole social), al estilo de las propuestas por Domingo Faustino Sarmiento o Andrés Bello en el Chile de la primera mitad del siglo XIX, propuestas que, en palabras de Narvaja de Arnoux (2008: 185), se inscriben "en un emprendimiento más amplio que es el desarrollo de una cultura hispanoamericana moderna para lo cual la marcación en la lengua escrita es la señal de cambio". El tiempo de las aventuras reformadoras de la ortografía, con plausibles fines democráticos y, de paso, de consolidación de la propia identidad, había pasado ya para los intelectuales y los gobernantes de los países hispanoamericanos de mediados del siglo XX. En efecto, el año de 1927 había significado el comienzo de la aceptación unánime, en todo el orbe hispanohablante, de la norma ortográfica impuesta por la Real Academia Española.

Serán, pues, otros los mecanismos discursivos de los que Nicasio $\mathrm{H}$. García se sirvió en este Plan concéntrico de ortografía para adoctrinar a sus jóvenes discípulos en la construcción de una identidad nacional y en su comportamiento como futuros ciudadanos en el seno de esa entidad política:

a) por una parte, son numerosos los ejemplos (vid. apéndice A) en los que se dan recomendaciones, máximas, sentencias, etc. relativas a la moral y la conducta que los alumnos deben seguir para aprender a ser ciudadanos responsables, trabajadores, honrados, saludables...;

b) por otra, son abundantes los ejemplos, ejercicios, textos de lectura, imágenes etc. (vid. apéndice B) que recurren a fuentes literarias de contenido patriótico, la inmensa mayoría de ellas pertenecientes a autores uruguayos o de otros países hispanoamericanos, así como a fuentes pictóricas de autores uruguayos; abundan también las alusiones políticas a los héroes libertadores o a otros símbolos nacionales; numerosas referencias geográficas, políticas y sociales mantienen vivos en la memoria nombres de accidentes geográficos propios de Uruguay, datos de la organización política del país y otros aspectos sociales; por último, otros muchos elementos autóctonos (nombres 
de plantas, objetos, peculiaridades climáticas, etc.) sirven para ubicar contextualmente la obra, además de insistir en algunos de los rasgos propios e identitarios del país en que se publica.

Posiblemente, este manual ortográfico no sea sino el eslabón de una larga cadena de textos escolares que en la historia de los dos últimos siglos de Uruguay pretendieron salvar la idiosincrasia del país (un país en continuo e intenso proceso de recepción de inmigrados) con la homogeneización de la cultura (priorizando la exaltación de lo autóctono) y la propagación de sus contenidos (lingüísticos y extralingüísticos) entre el mayor número posible de ciudadanos de todas las clases sociales, cuyo sistema de valores y comportamiento también pretendía regular. Como ha afirmado Narvaja de Arnoux (2008: 52) refiriéndose a Chile, pero con conclusiones perfectamente extrapolables al caso uruguayo, "la historia escolar construye el objeto nación, no sólo a través de operaciones cognitivas sino también emocionales".

\section{FINAL}

Con lo dicho hasta aquí, creemos haber conseguido un doble objetivo:

a) Por una parte, haber fundamentado la necesidad de la existencia de una subdisciplina provisionalmente llamada Etnortografia (denominación construida por analogía con las ya vistas Etnolexicografia y Etnogramática). Todas ellas, subdisciplinas de carácter metalingüístico, formarían parte del ámbito que se viene denominando actualmente Glotopolítica, esto es, el "campo que estudia las políticas lingüísticas y responde a demandas sociales respecto del planeamiento del lenguaje" (Narvaja de Arnoux 2008: 11) o, por expresarlo con las mismas palabras de quienes propusieron el término con esta acepción:

[Le terme glottopolitique] Il désigne les diverses approches qu'une société a de l'action sur le langage, qu'elle en soit ou non consciente: aussi bien la langue, quand la société légifère sur les statuts réciproques $\mathrm{du}$ français et des langues minoritaires par exemple; la parole, quand elle réprime tel emploi chez tel ou tel; le discours, quand l'école fait de la production de tel type de texte matière à examen: Glottopolitique est 
necéssaire pour englober tous les faits de langage où l'action de la société revêt la forme du politique (Guespin y Marcellesi 1986: 5) ${ }^{8}$.

En esquema:

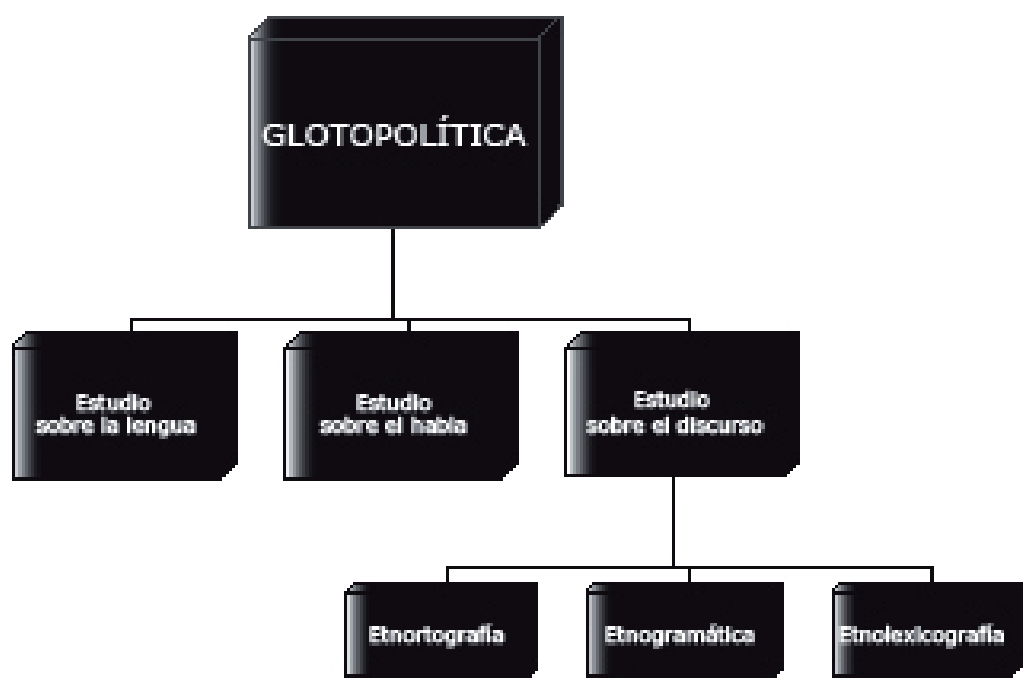

b) Por otra parte, haber realizado una nueva aportación, aunque mínima, a la historia de los textos escolares en Uruguay -en este caso, un manual ortográfico de mediados del siglo XX-, tarea en la que debemos citar a Zamorano (2004 y 2005) por haber estudiado alguno textos de gramáticas escolares (las de F. Gámez Marín y R. Abadíe \& H. Zarrilli) publicadas también en el mismo período histórico del sistema educativo uruguayo.

8 "[El término glotopolítica] designa los diversos enfoques que una sociedad presenta en su acción sobre el lenguaje, sea o no consciente de ello: tanto sobre la lengua, cuando por ejemplo la sociedad legisla sobre los estatutos recíprocos del francés y de las lenguas minoritarias; como sobre el habla, cuando reprime tal o cual uso en uno u otro; como sobre el discurso, cuando la escuela convierte en objeto de análisis la producción de un determinado tipo de texto: Glotopolítica es [un término] necesario para englobar todos aquellos hechos del lenguaje en los que la acción de la sociedad reviste la forma de lo político" (Guespin y Marcellesi 1986: 5) [trad. de MLCV]. 


\section{APÉNDICES}

\section{A.- EjEMPlos RElativos A LA MORALIDAD y LA CONDUCTA}

\begin{tabular}{|c|c|}
\hline $\begin{array}{l}\text { Recomendaciones, } \\
\text { máximas, } \\
\text { sentencias, etc. } \\
\text { relativas a la moral } \\
\text { y la conducta }\end{array}$ & $\begin{array}{l}\text { "Los niños deben saber jugar, tener orden para } \\
\text { comer y también para estudiar" (p. 41) } \\
\text { "No basta tener riquezas; es necesario saber } \\
\text { aprovecharlas" (p. 80) } \\
\text { "El hombre que bebe alcohol daña su salud" } \\
\text { (p. 91) } \\
\text { "El ahorro es la base de la fortuna" (p. 91) } \\
\text { "Quien ahorra hoy vive mañana libre de } \\
\text { inquietudes" (p. 91) } \\
\text { "El hombre honesto calma su hambre con el pan } \\
\text { ganado con su trabajo" (p. 92) } \\
\text { "El que a hierro mata a hierro muere" (p. 93) } \\
\text { "Amad siempre la verdad" (p. 101) } \\
\text { "Con voluntad se vencen todos los obstáculos" } \\
\text { (p. 101). } \\
\text { "Las frutas y las verduras comidas crudas son } \\
\text { de efecto tonificante" (p. 102) } \\
\text { "La acción del sol beneficia la salud" (p. 102) } \\
\text { "El uso del cepillo de dientes se debe hacer } \\
\text { diariamente" (p. 102) } \\
\text { "Es peligroso hablar mientras se mastican los } \\
\text { alimentos" (p. 102) } \\
\text { "La gimnasia asegura el buen desarrollo del } \\
\text { cuerpo" (p. 102) } \\
\text { "Apenas se siente un malestar en la garganta, } \\
\text { debe consultarse al médico" (p. 116) }\end{array}$ \\
\hline
\end{tabular}


B.- EJemplos ReLATivos Al CONTEXTO CULtuRAL, SOCIO-POLÍTICO Y GEOGRÁFICO

\begin{tabular}{|l|l|l|}
\hline Fuentes literarias & $\begin{array}{l}\text { De autores } \\
\text { uruguayos }\end{array}$ & $\begin{array}{l}\text { Juana de Ibarbourou (p. 135) } \\
\text { Fernán Silva Valdés (p. 136) } \\
\text { Eduardo Acevedo Díaz (p. } \\
137) \\
\text { Carlos Reyles (p. 137) }\end{array}$ \\
\cline { 2 - 3 } & $\begin{array}{l}\text { De otros } \\
\text { autores } \\
\text { hispano- } \\
\text { americanos }\end{array}$ & $\begin{array}{l}\text { Germán Berdiales (argentino) } \\
\text { (p. 136) }\end{array}$ \\
\cline { 2 - 3 } & $\begin{array}{l}\text { De autores } \\
\text { españoles }\end{array}$ & $\begin{array}{l}\text { Emilio Castelar: "La patria" } \\
\text { (p. 9) }\end{array}$ \\
\hline
\end{tabular}

\begin{tabular}{|l|l|l|}
\hline Fuentes pictóricas & $\begin{array}{l}\text { De autores } \\
\text { uruguayos }\end{array}$ & José Cúneo (lámina) \\
\hline
\end{tabular}

\begin{tabular}{|c|c|c|}
\hline Referencias políticas & $\begin{array}{l}\text { A los héroes } \\
\text { libertadores }\end{array}$ & $\begin{array}{l}\text { "Artigas venció en Las } \\
\text { Piedras" (p. 12) } \\
\text { "iLoor a Artigas, que nos } \\
\text { dio una patria libre! Leer los } \\
\text { episodios de su vida es deber } \\
\text { de todo uruguayo" (p. 15) } \\
\text { "Artigas nos enseñó a creer } \\
\text { en el alma de nuestro pueblo" } \\
\text { (p. 17) } \\
\text { "Artigas, Bolívar y San } \\
\text { Martín fueron tres grandes } \\
\text { héroes” (p. 47) } \\
\text { "Los héroes americanos } \\
\text { defendieron la libertad de } \\
\text { nuestro continente" (p. 91) } \\
\text { "¿Cuántos hombres llevaron a } \\
\text { cabo la Cruzada Libertadora?” } \\
\text { (p. 100) } \\
\text { "Dijo Artigas: sean los } \\
\text { orientales tan ilustrados como } \\
\text { valientes" (p. 123) }\end{array}$ \\
\hline
\end{tabular}




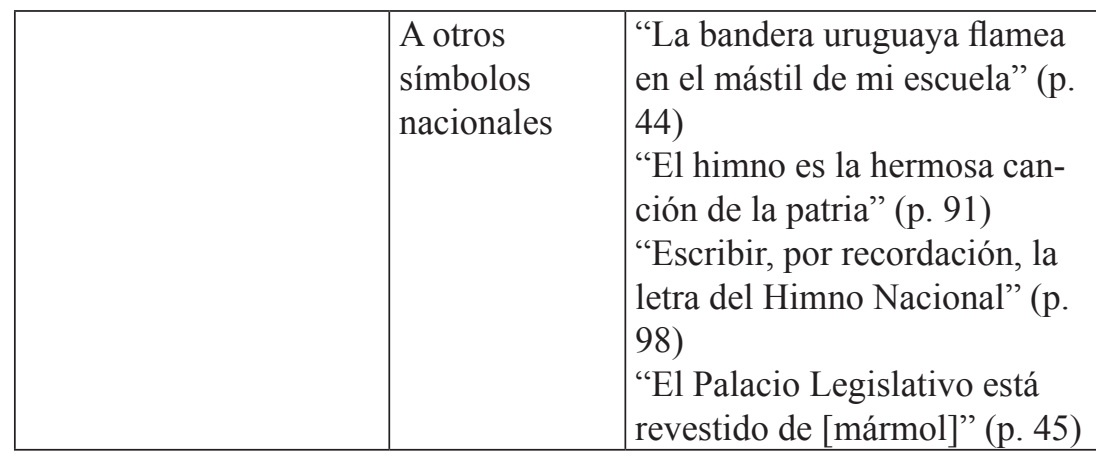

\begin{tabular}{|c|c|c|}
\hline \multirow[t]{2}{*}{$\begin{array}{l}\text { Referencias } \\
\text { geográficas, } \\
\text { políticas y sociales }\end{array}$} & $\begin{array}{l}\text { Accidentes } \\
\text { geográficos }\end{array}$ & $\begin{array}{l}\text { "El río Negro atraviesa nues- } \\
\text { tro país de este a oeste" (p. } \\
\text { 12) } \\
\text { "Las aguas del río Santa Lucía } \\
\text { se beben en Montevideo" (p. } \\
\text { 15) } \\
\text { "El océano [Atlántico] baña } \\
\text { las costas de Rocha” (p. 23) } \\
\text { "Queríamos ver las maravillas } \\
\text { del río Uruguay” (p. 35) } \\
\text { "Esta inmensa corriente de } \\
\text { agua une a dos países vecinos } \\
\text { y amigos” (p. 35) } \\
\text { "El río Cuareim une dos paí- } \\
\text { ses hermanos" (p. 101). } \\
\text { “Por qué los indios llamaban } \\
\text { al Plata Paraná Guazú”? (p. } \\
\text { 126) }\end{array}$ \\
\hline & $\begin{array}{l}\text { Organización } \\
\text { geopolítica }\end{array}$ & $\begin{array}{l}\text { "Montevideo es la capital } \\
\text { de la República Oriental del } \\
\text { Uruguay" (p. 12) } \\
\text { "Escribir en forma de colum- } \\
\text { na el nombre de los departa- } \\
\text { mentos de la República y de } \\
\text { sus capitales" (p. 22) } \\
\text { "El Uruguay tiene cerca de } \\
\text { tres millones de habitantes" } \\
\text { (p.91) }\end{array}$ \\
\hline
\end{tabular}




\begin{tabular}{|c|c|c|}
\hline & & $\begin{array}{l}\text { "¿Cuántos departamentos tiene } \\
\text { la Rca. Oriental del Uruguay?" } \\
\text { (p. 100) } \\
\text { "Montevideo, Treinta y Tres, } \\
\text { Paysandú y Cerro Largo son } \\
\text { departamentos de la Rca. } \\
\text { Oriental del Uruguay” (p. 123) }\end{array}$ \\
\hline & \begin{tabular}{|l|} 
Aspectos \\
sociales
\end{tabular} & $\begin{array}{l}\text { "Este país es mío" poema sin } \\
\text { autor) (p. 15) } \\
\text { "Lo que sé del Uruguay" } \\
\text { (ejercicio de redacción) (p. 18) } \\
\text { "Nuestro país recibe a todos } \\
\text { los hombres del mundo que se } \\
\text { aproximan a su suelo en busca } \\
\text { de paz y de buen éxito en su } \\
\text { trabajo" (p. 115) }\end{array}$ \\
\hline
\end{tabular}

\begin{tabular}{|c|c|c|}
\hline \multirow[t]{4}{*}{$\begin{array}{l}\text { Otros aspectos } \\
\text { autóctonos }\end{array}$} & $\begin{array}{l}\text { Nombres } \\
\text { de diarios } \\
\text { uruguayos (p. } \\
11 \text { ) }\end{array}$ & $\begin{array}{l}\text { El Día } \\
\text { Mundo Uruguayo } \\
\text { La Nación }\end{array}$ \\
\hline & $\begin{array}{l}\text { Nombres de } \\
\text { plantas }\end{array}$ & $\begin{array}{l}\text { "Ajíes" [pimientos] (p. 14) } \\
\text { "La raíz del ombú sirve de } \\
\text { asiento al paisano" (p. 15) } \\
\text { "El tala y el espinillo tienen } \\
\text { fuertes púas" (p. 15) }\end{array}$ \\
\hline & $\begin{array}{l}\text { Poblaciones } \\
\text { indígenas }\end{array}$ & $\begin{array}{l}\text { "Los charrúas vivían en el sur } \\
\text { de este país" (p. 15) } \\
\text { "Las armas de los indios eran } \\
\text { las boleadoras y las flechas" } \\
\text { (p. 23) }\end{array}$ \\
\hline & $\begin{array}{l}\text { Nombres de } \\
\text { monedas }\end{array}$ & $\begin{array}{l}\text { “¡Hermosas cebollas a } \\
\text { cincuenta centésimos el } \\
\text { ciento!” (p. 76) } \\
\text { “Cómo gastaría diez pesos?” } \\
\text { (p. 100) }\end{array}$ \\
\hline
\end{tabular}




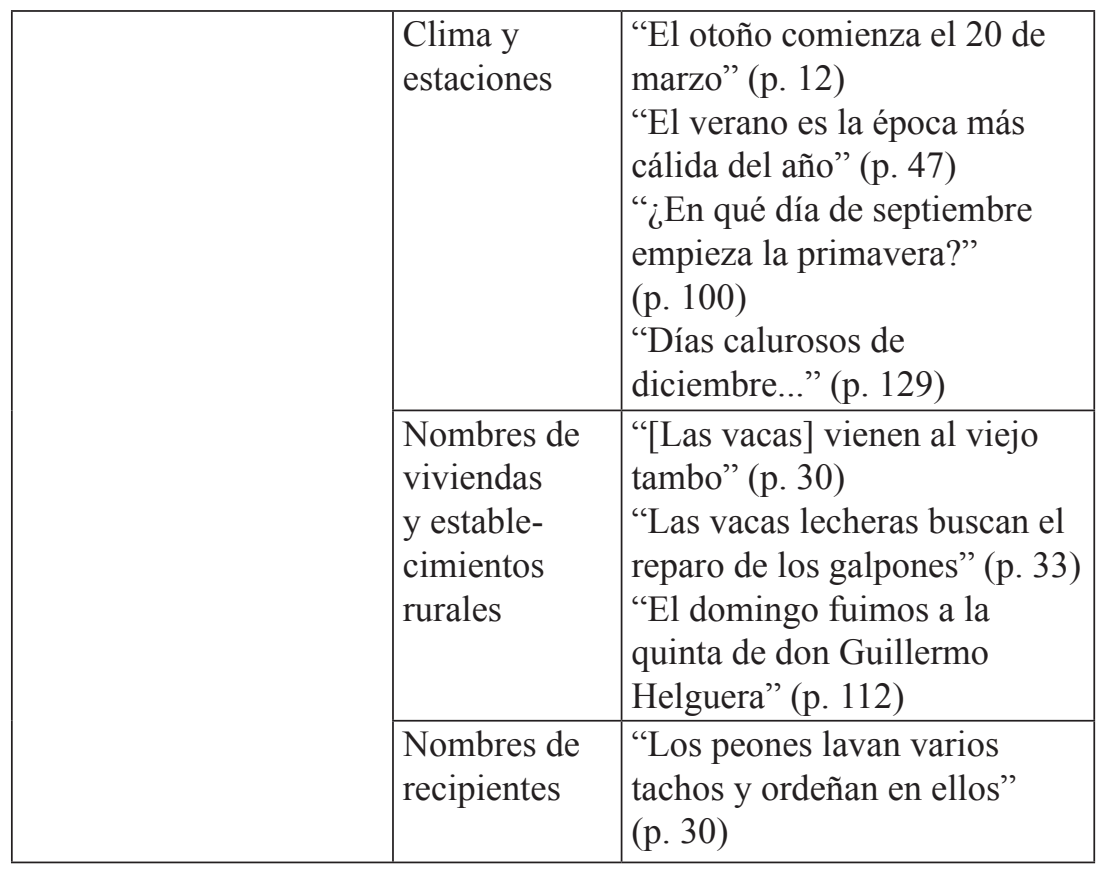

\section{REFERENCIAS BIBLIOGRÁFICAS}

Ahumada Lara, Ignacio (ed.). 2006. Diccionario bibliográfico de la metalexicografía del español (Orígenes-año 2000). Jaén: Universidad de Jaén (Seminario de Lexicografía Hispánica).

Blecua Perdices, José Manuel. 1990. Diccionario y enunciación. En Profesor Francisco Marsá. Jornadas de Filología, pp. 61-74. Barcelona: Universidad de Barcelona.

Calero Vaquera, $M^{a}$ Luisa. 2004. Métodos de enseñanza gramatical en la tradición: propuesta de nueva disciplina. En Cristóbal Corrales et al. (eds.). Nuevas aportaciones a la historiografia lingüística (Actas del IV Congreso Internacional de la SEHL), pp. 317-326. Madrid: Arco/Libros, vol. I.

Casares, Julio. 1992 [1950]. Introducción a la lexicografia moderna. Madrid: CSIC.

Celis M., Luis. 2010. Expresiones ideológicas en los debates educacionales en Chile (1860-1930). Disponible en http://webcache.googleusercontent.com/search?q=cache: JxdgjyBjGQgJ:historia.fcs.ucr.ac.cr/congr-ed/o-paises/Chile/Ponencia\%2520Luis\%252 0 Celis.doc+expresiones + ideol $\%$ C3\%B3gicas + en + los + debates + educacionales + en + Chil $\mathrm{e} \& \mathrm{~cd}=1 \& \mathrm{hl}=\mathrm{es} \& \mathrm{ct}=\mathrm{clnk} \& \mathrm{gl}=\mathrm{es}$ [Consulta $01 / 05 / 2010]$.

Dijk, Teun A. van. 1998. Ideología: un enfoque multidisciplinario. Barcelona: Gedisa.

Fernández, Mirta, Virginia Piriz, Diego Ribas y Silvia Spinak. 2000. El trabajo: presencia explícita o implícita en los textos oficiales para la enseñanza de la lectura en las escuelas 
públicas uruguayas (1927-1941). En Trabajos de investigación del Museo Pedagógico José Pedro Varela. Disponible en http://www.crnti.edu.uy/museo/imagen/trabajo.doc [Consulta: 30/04/2010].

Forgas Berdet, Esther. 1996. Lengua, sociedad y diccionario: La ideología. En Esther Forgas (coord.). Léxico y diccionario, pp. 71-90. Tarragona: Universitat Rovira i Virgili, Departament de Filologies Romàniques.

Forgas Berdet, Esther. 2001. Mujer y diccionario: lo femenino en los ejemplos lexicográficos. Hispanista (Revista electrónica de los hispanistas de Brasil), II, $\mathrm{n}^{\circ}$ 5, abril, mayo y junio.

García, Nicasio H. 1947. Plan concéntrico de ortografía. Curso elemental. Montevideo: Libreros-Editores A. Monteverde y Cía.

Guespin, Louis y Jean-Baptiste Marcellesi. 1986. Pour la glottopolitique. Langages 83: 534.

Lledó, Eulalia (coord.), Ma Ángeles Calero y Esther Forgas. 2004. De mujeres y diccionarios. Evolución de lo femenino en la $22^{a}$ edición del DRAE. Madrid: Instituto de la Mujer (Ministerio de Trabajo y Asuntos Sociales).

Martinell, Montserrat. 1984. Gramática y moral (Resumen de comunicación). Revista Española de Lingüistica 14 (1): 168-169.

Medina Guerra, Antonia Ma (ed.). 2003. Lexicografia española. Barcelona: Ariel Lingüística.

Miguel, Raimundo DE. 1882. Gramática hispano-latina, teórico-práctica para el estudio simultáneo de las lenguas latina y castellana comparadas. Madrid: A. Jubera.

Narvaja de ARnoux, ElviRa. 2008. Los discursos sobre la nación y el lenguaje en la formación del Estado (Chile, 1842-1862). Estudio glotopolítico. Buenos Aires: Santiago Arcos editor.

Pascual, José Antonio y Ma del Carmen Olaguíbel. 1992. Ideología y diccionario. En Ignacio Ahumada (ed.). Diccionarios españoles: contenidos y aplicaciones. Lecciones del I Seminario de Lexicografía Hispánica (Jaén, 21-24 de enero de 1991), pp. 73-89. Jaén: Casa Editora El Estudiante.

Pérez Cuadrado, Cosme. 1946. Curso superior de Gramática española simbólica e intuitiva. Madrid: Ediciones Atlas.

Pérez Hernández, Francisco Javier. 1997. Estudios de lexicografía venezolana (Historia y lexicografia antigua, metalexicografia y etnolexicografia). Caracas: La Casa de Bello.

-2000. Diccionarios, discursos etnográficos, universos léxicos: propuestas teóricas para la comprensión cultural de los diccionarios. Caracas: Fundación Centro Estudios Latinoamericanos Rómulo Gallegos / Universidad Católica Andrés Bello.

Rodríguez Barcia, Susana. 2008. La realidad relativa. Evolución ideológica en el trabajo lexicográfico de la Real Academia Española (1726-2006). Vigo: Servizo de Publicacións.

Seco, Manuel. 1987. Estudios de lexicografia española. Madrid: Paraninfo.

Swiggers, Pierre y Nico Lioce. 2003. Grammaire, réalité et image du monde dans les Leys d'Amors. En Rossana Castano, Saverio Guida y Fortunata Latella (éds.). Scène, évolution, sort de la langue et de la littérature d'oc, t. I, pp. 675-684. Roma: Viella.

Zamorano Aguilar, Alfonso. 2004. Historia de la gramática española en América (II). Uruguay. Los manuales escolares de R. Abadíe Soriano y H. Zarrilli $(1924,1937)$. Ed.Uco 3: 71-100.

2005. Historia de la gramática española en América (I). Uruguay. A propósito de Francisco Gámez Marín (1868-1932). Revista de Lingüística Teórica y Aplicada, 43 (2): $85-118$.

Zarrilli, Humberto y Roberto Abadí Soriano. 1943. Libro Primero de Lectura. Ilustraciones de Héctor Fernández y González. Montevideo: Impresores Colombinos Hnos. 